Brit. J. industr. Med., 1954, 11, 167.

\title{
SOME TOXIC PROPERTIES OF DIMETHYLNITROSAMINE
}

\author{
BY \\ J. M. BARNES and P. N. MAGEE \\ From the Toxicology Research Unit, Serum Research Institute, Woodmansterne Road, \\ Carshalton Beeches, Surrey
}

(RECEIVED FOR PUBLICATION MAY 22, 1954)

The appearance of two cases of cirrhosis of the liver among three men working in the research laboratory of a large industrial undertaking led to suspicion becoming attached to dimethylnitrosamine (D.M.N.) as the causative agent. Dimethylnitrosamine had been introduced into the laboratory as a solvent about 10 months before the first case of cirrhosis was discovered. One of the men had died of bronchopneumonia, and cirrhosis of the liver was an incidental finding at necropsy. The second man with a long-standing history of dyspepsia had a laparotomy after five months' exposure to D.M.N. At that time no note of any abnormality of the liver was made. Six months later he was examined for an incisional hernia that had developed in the operation scar. It was then recorded that the liver felt hard and was suspected of being cirrhotic. Liver function tests carried out at this time showed evidence of damage. When repeated three months later after all further exposure to D.M.N. had ceased these tests indicated an improved liver function. The third man has remained in good health but has had no liver function tests carried out on him.

A search of the literature revealed only a single short report of the toxic properties of D.M.N. (Hamilton and Hardy, 1949). Dimethylnitrosamine had been used in an automobile factory and some illness had followed. Experiments on dogs showed it to be capable of producing severe liver injury, but no experimental details are provided. The medical officer of the firm therefore asked if we would examine the toxic properties of D.M.N. towards laboratory animals.

Dimethylnitrosamine, $\underset{\mathrm{CH}_{3}}{\mathrm{CH}_{3}}>\mathrm{N}$.NO, is a mobile yellow liquid with a faint, characteristic odour. It boils at $151^{\circ} \mathrm{C}$. and its specific gravity is 1.015 at $20^{\circ} \mathrm{C}$. It is miscible in all proportions with water, ethyl alcohol, methylene chloride, or vegetable oil. Under ordinary conditions it is a stable substance, but with zinc dust and acetic acid it can be reduced to dimethylhydrazine $\underset{\mathrm{CH}_{3}}{\mathrm{CH}_{3}}>\mathrm{N} . \mathrm{NH}_{2}$.

Preliminary experiments revealed that D.M.N. readily produced a severe liver injury and this paper gives an account of some of the features of the lesions.

\section{Materials and Methods}

The D.M.N. was a sample of pure material specially prepared by the firm who had both made and used the D.M.N.

Male and female albino rats were used in the majority of the experiments. Additional observations were made on mice, guinea-pigs, rabbits, and dogs.

For single oral doses a solution of D.M.N. in water was administered. For injection either an aqueous solution was used or the undiluted D.M.N. was given by a micro-syringe. Percutaneous absorption was studied on rats depilated with barium sulphide. The D.M.N. was applied undiluted and the skin left uncovered. The rats were placed in small individual wire cages for four hours after each dose so that they could not lick themselves.

For the feeding experiments solutions of D.M.N. were made up in arachis oil. These solutions were added at the rate of $10 \mathrm{ml} . / \mathrm{kg}$. of powdered rat diet (M.R.C. diet 41).

For histological work animals were killed with coal gas unless already dead. Tissues were fixed in $10 \%$ formol-saline and in Helly's fluid. Paraffin sections cut at $7 \mu$ were stained by haematoxylin and eosin, by the van Gieson and the Mallory azocarmine methods for connective tissue, Gomori's silver method for reticulin, and by the periodic-acid-Schiff technique (McManus, 1946). Frozen sections of material fixed in formolsaline were stained with Sudan IV. Sections of pancreas, after fixation in Bouin's fluid, were stained by the aldehyde fuchsin and the chromium haematoxylin phloxin methods (Gomori, 1941, 1950).

\section{Results}

Acute Poisoning.- - In all species examined a single lethal dose of D.M.N. by mouth or by injection 
produced extensive liver necrosis but the differences in the reactions of each species merit a separate description.

Rats.-The L.D. 50 by intraperitoneal injection was $26 \cdot 5(20 \cdot 5-34 \cdot 2) \mathrm{mg}$. $/ \mathrm{kg}$. calculating the results by the method of Weil (1952). Although the response of rats to an oral dose varied somewhat in different experiments, the average lethal dose was less than $50 \mathrm{mg} . / \mathrm{kg}$. The rats never died in less than two days or more than six days after a single oral dose. They appeared ill, sitting quietly with ruffled coats, but displayed no other sign of poisoning except that abdominal swelling was visible in some animals surviving several days.

At necropsy there was a variable amount of bloodstained fluid in the peritoneal cavity. The volume might exceed $30 \mathrm{ml}$. and sometimes had a colour and consistency approaching that of pure blood. The omentum and pancreas often had a jelly-like oedema in their interstices, and subcutaneous oedema over the abdominal wall was occasionally seen. Haemorrhage into the lumen of the upper part of the intestine was sometimes observed. The liver was swollen, dark and mottled, and somewhat friable. Apart from a little clear pericardial and pleural exudate in some animals there were no other lesions visible to naked-eye examination. Haemorrhage was confined to the peritoneal cavity and lumen of the gut. In a number of animals where this was pronounced, the possibility that cerebral haemorrhage might have occurred was excluded by direct examination.

A dose of 40 to $50 \mathrm{mg}$. $/ \mathrm{kg}$. had a similar effect whether given by mouth, by intravenous, intraperitoneal, or subcutaneous injection. But acute poisoning could not be produced by percutaneous application of undiluted D.M.N. A dose of 100 $\mathrm{mg}$./kg. applied on four successive days had no effect on the general condition of six rats.

Rabbits.-A dose of $15 \mathrm{mg}$. $/ \mathrm{kg}$. killed rabbits in less than 24 hours. Those given $10 \mathrm{mg}$. $/ \mathrm{kg}$. either died in less than 24 hours or survived at least 10 days. A straw-coloured peritoneal exudate was usually present at death but it was never haemorrhagic. The liver was large, dark, and friable but no other lesions were visible to naked-eye examination.

Mice.-Mice behaved like rabbits. Death always took place within 30 hours and all mice receiving $20 \mathrm{mg}$. $/ \mathrm{kg}$. died. Any peritoneal fluid present at death was clear. The livers were swollen, red, and mottled.

Guinea-pigs.-Eight animals receiving doses of 25 to $50 \mathrm{mg}$. $/ \mathrm{kg}$. all died, but none in less than four days or more than eight days after the D.M.N. In the majority a haemorrhagic peritoneal exudate was present at death and the liver was congested and mottled.

Dogs.-One dog was given a single oral dose of $50 \mathrm{mg}$. $/ \mathrm{kg}$. An hour later it vomited several times. Next morning it was conscious but unable to stand and died quietly 20 hours after receiving the D.M.N. At necropsy the peritoneum contained about $100 \mathrm{ml}$. of bright red blood and the stomach and gut were full of blood, some obviously recently shed. There were no other lesions or haemorrhages. The liver was not grossly abnormal to naked-eye examination.

A second dog died in less than 24 hours after a single oral dose of $20 \mathrm{mg}$. $/ \mathrm{kg}$. Again it vomited repeatedly soon after the D.M.N. Within six hours it was comatose though moved when touched. At necropsy there was no peritoneal haemorrhage but the stomach and upper parts of the gut contained much bright red blood. The liver appeared congested.

A third dog received $10 \mathrm{mg}$. $/ \mathrm{kg}$. by mouth on three separate occasions. Eight days elapsed between the first and second doses and four days between the second and third. It vomited about an hour after the first two doses. It was not obviously ill until the seventh day after the last dose, when it was found unconscious in the morning. At necropsy there was about $100 \mathrm{ml}$. of fluid resembling pure blood in the peritoneal cavity. The stomach and small intestine contained a black fluid and the bowel contained typical melaena. There were no erosions in the stomach. The mesenteric lymph nodes were red. The liver was firm and tense; the cut surface was mottled and had a " nutmeg" appearance. There was no obstruction or gross lesion within the lumen of the hepatic vein. The pleural and pericardial cavities and the lungs were healthy.

Subacute Effects.-Rats that lived for seven days or more after a dose of 20 to $40 \mathrm{mg}$. $/ \mathrm{kg}$. frequently appeared ill and ate little. They had a pronounced abdominal swelling due to fluid that could be aspirated. This fluid accumulation masked any loss of weight due to emaciation. The liver was of variable size and often irregular in outline. In some animals it showed evidence of fibrosis.

Two rabbits surviving a dose of $10 \mathrm{mg} . / \mathrm{kg}$. appeared ill 10 days later and at necropsy both had some peritoneal exudate and small, symmetrically shrunken livers.

Chronic Poisoning.-Chronic poisoning was produced by giving a diet containing 50,100 , and 200 parts per million (p.p.m.) D.M.N. to groups 
of six young rats. The reactions of the groups were as follows :-

50 p.p.m.-After 110 days on the diet the mean weight of the group on D.M.N. was significantly lower than that of the control group. No rats died nor was anything abnormal noted at necropsy on those killed at this time.

100 p.p.m.-All the rats died after 62 to 95 days on the diet. At 60 days the mean weight of the group was only $65 \%$ of that of the controls.

200 p.p.m.-All rats died or were killed in extremis after 34 to 37 days on the diet. At necropsy all rats in the last two groups showed extreme emaciation and complete absence of body fat. The food intake was unaffected during the first two weeks on these diets indicating that D.M.N. in the concentration used did not reduce the palatability of the diet. Emaciation must have been the result of the toxic effects of D.M.N. Gross peritoneal exudate was not seen in these animals but in some there was evidence of recent haemorrhage into the gut. The retroperitoneal and retrosternal lymph glands were sometimes red. The liver was small and in those dying later there was obvious fibrosis. The pleural surfaces of the lungs often showed a number of discrete brown stains scattered over them.

\section{Histological Observations}

Liver.-A detailed account of the changes seen in the rat is given and findings in the other species briefly compared. A single dose of 5 to $10 \mathrm{mg}$. D.M.N./kg. produced no significant damage, but a dose of $20 \mathrm{mg} . / \mathrm{kg}$. or above led to characteristic changes. Within six hours there was a pallor of the centrilobular and midzone regions where the liver cells showed an eosinophilia of the cytoplasm greater than in those cells in the periportal zones. The central veins were moderately congested and the sinusoids dilated. Fat staining showed a deposition of fine sudanophilic droplets in the cells of the centrilobular areas. In the same area glycogen was depleted.

At 18 hours the changes were more conspicuous though still confined to the centrilobular and midzone regions. The parenchymal cells were obviously damaged. The cytoplasm was amorphous and eosinophilic, frequently vacuolated but only rarely to the extent of producing large hydropic cells (Fig. 1). The nuclei were swollen, pale and irregular in outline. The periportal zone and portal tracts were unaffected. The contrast was more striking in sections stained for fat. The periportal areas were free from any deposit of sudanophilic material (Fig. 2). Glycogen was almost completely absent.
By 24 hours the necrosis of the centrilobular and midzone cells was general. The necrotic areas were becoming confluent and haemorrhage into them was frequent. The isolated periportal areas of apparently healthy liver cells were surrounded by bands of congested necrotic tissie. The reticular framework remained intact.

By 48 hours this pseudo-lobular appearance was very marked (Fig. 3) and the necrotic bands were haemorrhagic. The red blood cells showed evidence of degeneration. There was an early invasion of the damaged area by polymorphonuclear cells. The proportion of necrotic to apparently healthy tissue varied considerably from animal to animal but the general picture was the same. By this time active regeneration as witnessed by numerous mitotic figures and binucleate cells had started (Fig. 4). The reticular pattern was preserved but the reticuloendothelial cells were swollen and deeply stained but not obviously damaged. The portal tracts were normal.

By 72 hours the areas of necrosis had begun to shrink and were separated from the regenerating parenchyma by empty clefts (probably artefacts) (Fig. 5). This gave the lesions a "punched out" appearance. The necrotic areas contained only polymorphs and reticulo-endothelial cells among the debris and a few nuclear remnants from the parenchymal cells. The reticulin framework and the central veins were intact (Figs. 6 and 7).

Sections from animals killed at a later stage were almost certainly from animals that would have ultimately survived. The picture was very variable depending as it must upon the extent of the original injury. There was a progressive shrinkage of the necrotic areas and its replacement by actively growing liver cells from the undamaged areas. At first the regenerated areas showed irregular arrangement of the cells but by 17 days the liver had almost regained its normal appearance with only occasional fine strands of young connective tissue as a reminder of the pre-existing necrosis. In one animal killed 17 days after a dose of $45 \mathrm{mg} . / \mathrm{kg}$. there was evidence of incomplete repair with persistent islands of necrosis and more prominent branches of young connective tissue.

The livers of rats dying while being fed diets containing 200 and 100 p.p.m. of D.M.N. showed a similar picture of acute liver injury with considerable variation in degree from animal to animal. The islands of periportal tissue often contained parenchymal cells with unusual nuclear forms but rarely showing mitosis. There was little fatty change and glycogen was always absent. The bands of necrotic tissue might show variation in the proportion 


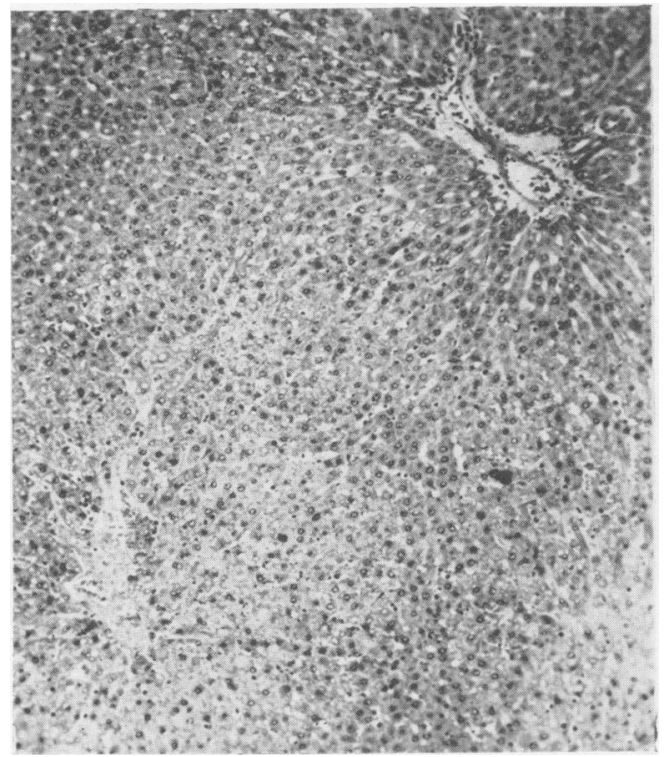

FIG. 1.-Rat liver after ingestion of D.M.N., $50 \mathrm{mg}$. per kg., for 18 hours. Haematoxylin and eosin. Early centrilobular and midzonal necrosis. $\times 100$.

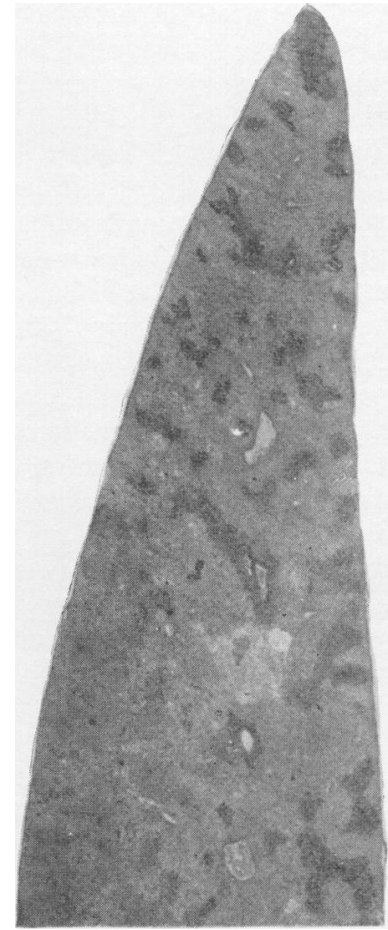

Fig. 3.-Rat liver after ingestion of D.M.N., $30 \mathrm{mg}$. per kg., for 48 hours. Haematoxylin and eosin. The darker areas of surviving periportal parenchyma are isolated by large confluent zones of necrosis. $\times 18$.

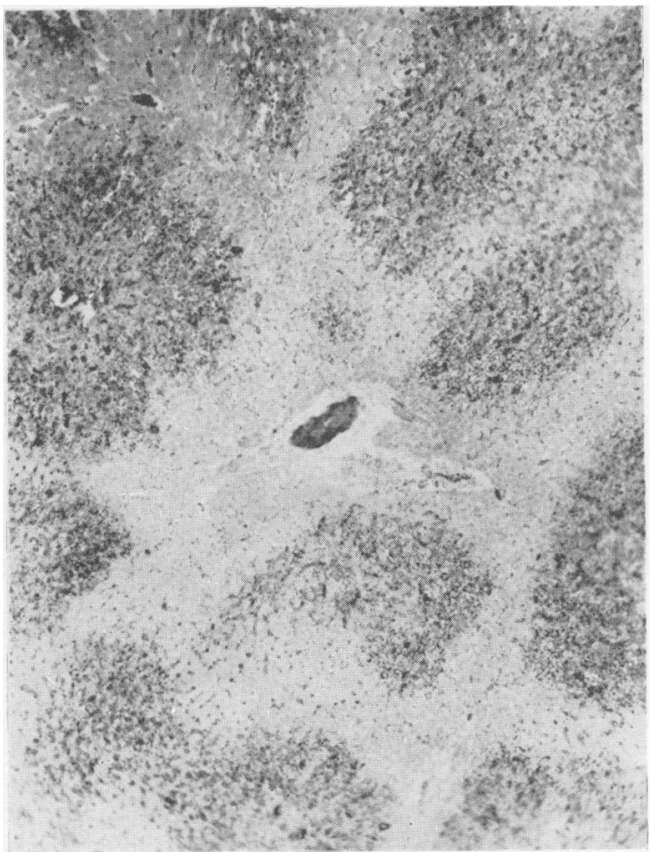

FIG. 2.-Rat liver after ingestion of D.M.N., $50 \mathrm{mg}$. per kg., for 18 hours. Sudan IV green filter. The pale areas represent surviving periportal parenchyma: the darker areas represent the necrotic zones containing many sudanophil droplets. $\times 60$

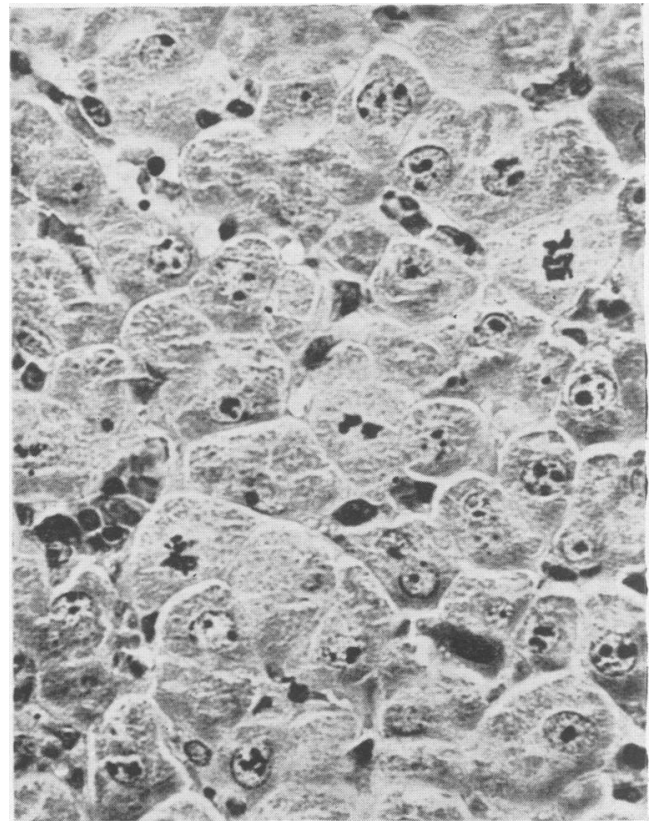

FIG. 4.-Rat liver after ingestion of D.M.N., $30 \mathrm{mg}$. per kg. for 48 hours. Haematoxylin and eosin. Regenerating parenchymal cells with three mitotic figures. $\times 500$. 


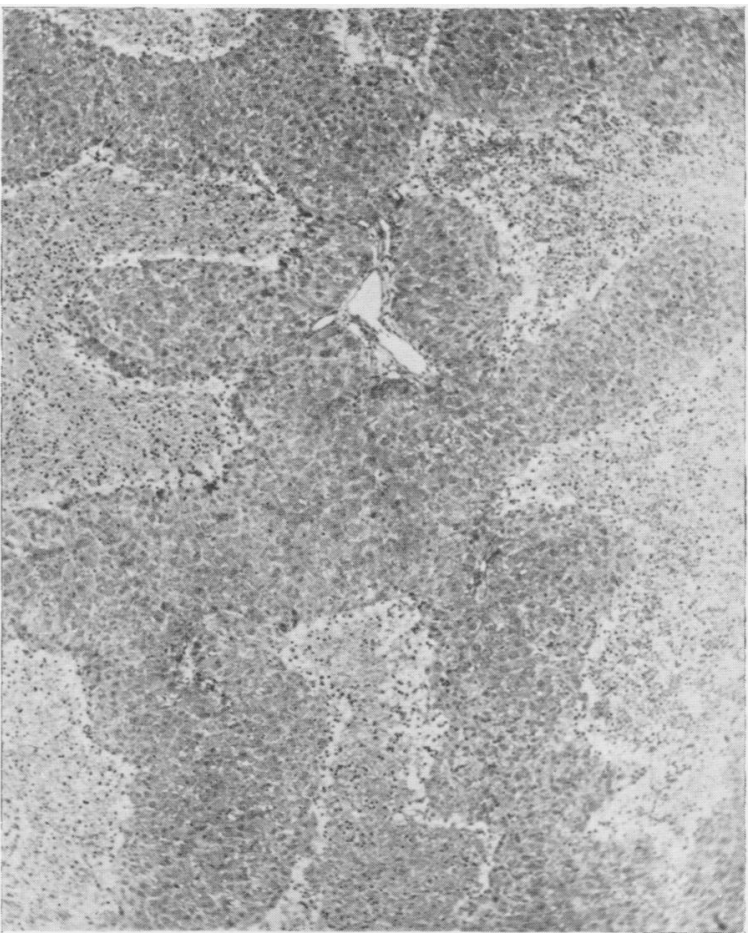

FIG. 5.-Rat liver after ingestion of D.M.N., $50 \mathrm{mg}$. per kg., for 72 hours. Haematoxylin and eosin. The necrotic zones are abruptly demarcated from the regenerating parenchyma. $\times 60$.

of its different constituents-degenerating hepati: cells, red cells and red-cell debris, macrophages, fibroblasts, and young connective tissue (Fig. 8).

In those surviving longest there was some bile duct proliferation and more fibrous tissue (Fig. 9). There was often a deposit of a yellow pigment staining for iron.

A histological picture similar to that in the rat was seen in the liver of the dog, with typical centrilobular haemorrhagic necrosis extending out into the midzones and leaving only narrow rims of surviving parenchyma around the portal tracts. The portal veins showed severe congestion and dilatation and there was frequent haemorrhage into the connective tissue of the portal tracts. The lymphatics of the portal tracts were widely dilated. The hepatic veins were patent. In the rabbits and mice there was less evidence of a zonal injury to the liver lobules and the effect more closely resembled that of a massive necrosis (Himsworth, 1947). In neither species did animals survive more than 30 hours after the administration of D.M.N.

Other Organs.-These showed little change. The lungs were congested and sometimes showed small

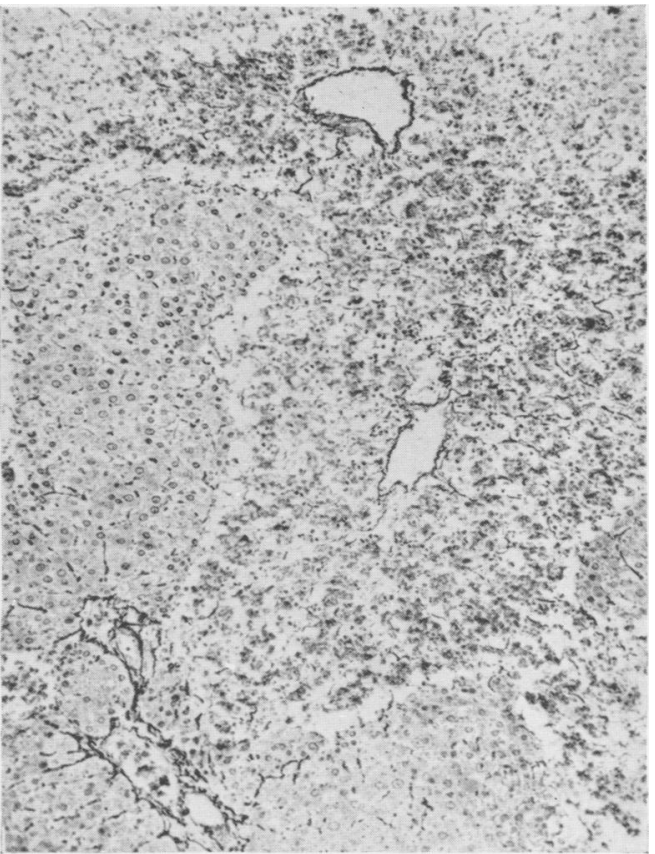

FIG. 6.-Rat liver after ingestion of D.M.N., $50 \mathrm{mg}$. per kg., for $\mathbf{7 2}$ hours. Gomori silver impregnation. The reticular network persists in the necrotic area with no obvious reduction in the distance between the hepatic vein and the portal tract. $\times 100$.

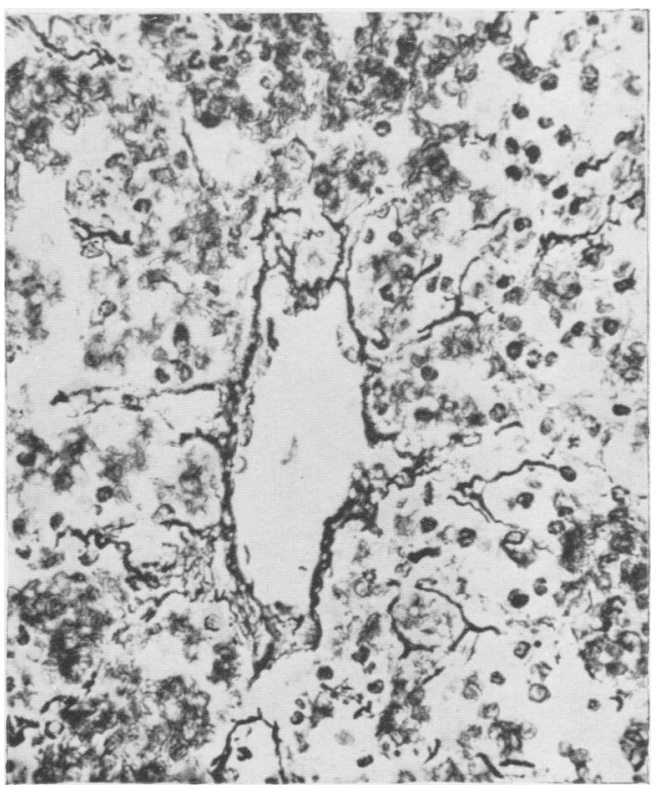

FIG. 7.-Rat liver after ingestion of D.M.N., $50 \mathrm{mg}$. per kg., for 72 hours. Gomori silver impregnation. Same preparation as Fig. 6 to show intact central vein, also persisting reticular strands in the necrotic tissue. $\times \mathbf{4 0 0}$. 


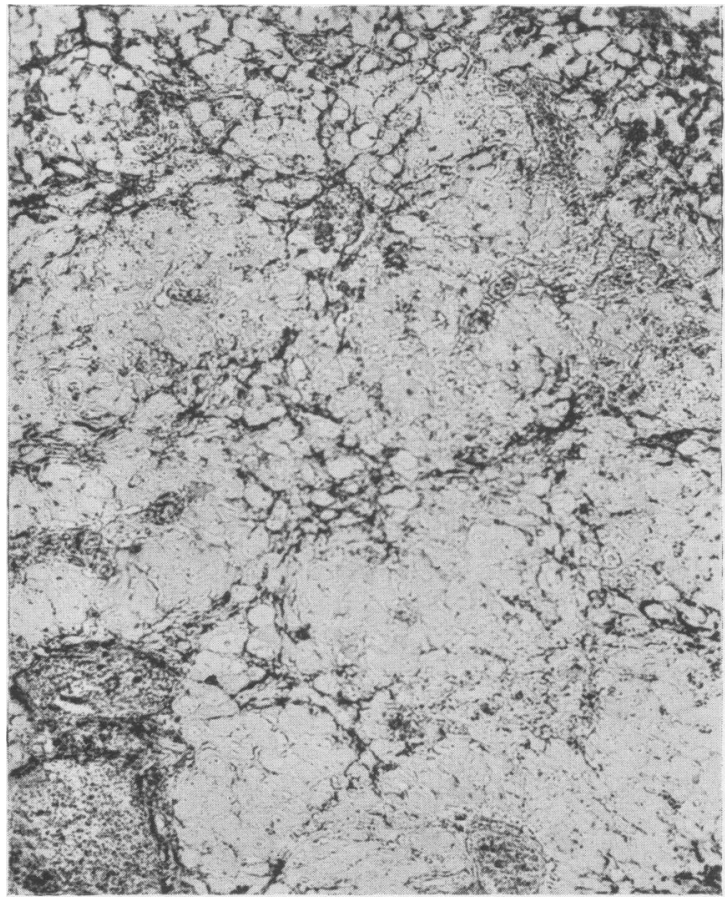

FIG. 8.-Rat liver after ingestion of D.M.N., 100 p.p.m., for nine weeks. Mallory's azocarmine. Irregular formation of fibrous tissue. $\times 100$.

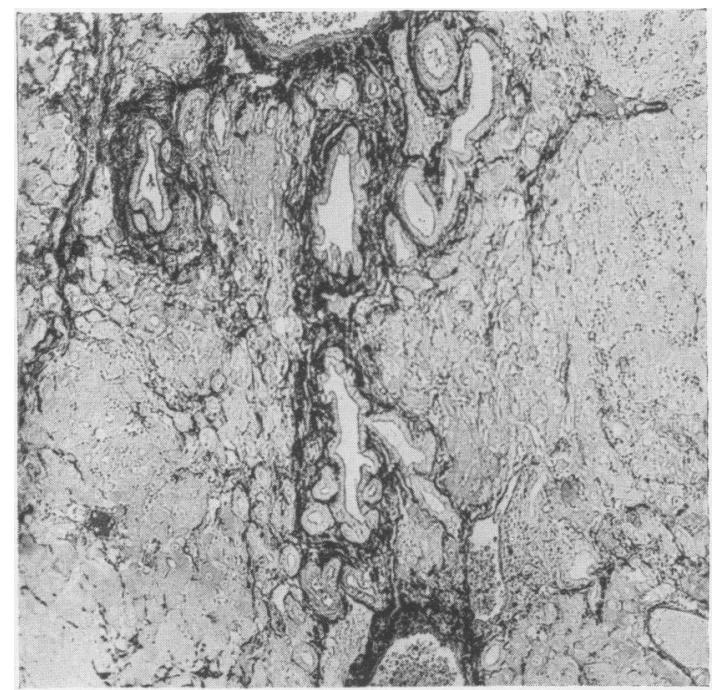

FIG. 9.-Rat liver after ingestion of D.M.N., 100 p.p.m., for nine weeks. Mallory's azocarmine. Same preparation as Fig. 8 showing fibrous tissue and bile duct proliferation. $\times 100$. haemorrhagic areas. The kidneys were normal. The spleen had a reduced red cell content and a more prominent reticulo-endothelial component. The retrosternal lymph glands contained amorphous eosinophilic debris, degenerating erythrocytes and macrophages filled with yellow-brown pigment. In the dog there was no evidence of congestion in the gastro-intestinal tract and the mucous membrane was well preserved.

\section{Discussion}

Dimethylnitrosamine appears to act primarily as a liver poison producing severe liver necrosis in rats, mice, rabbits, guinea-pigs, and dogs. The species examined seem to be more or less equally susceptible to D.M.N. and the general picture of poisoning is consistent with that following a severe liver injury. Some features of the condition merit further discussion.

The haemorrhagic peritoneal exudate and the bleeding into the lumen of the gut are striking features of poisoning in rats, dogs, and guinea-pigs. It has not been described in animals with liver injury following carbon tetrachloride, beryllium, phosphorus, or diphtheria toxin, for example. However, poisoning by senecio (ragwort) can produce liver damage and internal haemorrhage in horses and cattle and the condition has been produced experimentally in rats (Davidson, 1935). Although the loss of blood may be a contributory cause of death after D.M.N. in those species in which it occurs, death is just as rapid in those species in which there is no haemorrhage. Dimethylnitrosamine produces no histological evidence of widespread damage to any important organ other than the liver. The congestion and other signs of injury in the lungs were probably terminal.

Like carbon tetrachloride, D.M.N. produces a centrilobular necrosis and complete recovery is possible after the extensive damage produced by a single near-lethal dose. Repeated doses, as in the feeding experiment, may lead to fibrosis. However, the lesions due to D.M.N. differ from those due to carbon tetrachloride in that they are haemorrhagic and show a sharp transition from the damaged to undamaged liver tissue. In the central part of the lobule the hepatic cells appear totally destroyed while at the periphery they appear normal. The swollen hydropic or otherwise apparently injured liver cells are rarely seen after D.M.N.

In some respects the distribution of the lesions gives the liver the nutmeg appearance associated with passive venous congestion. In dogs a centrilobular necrosis that resembles the lesions of chloroform poisoning has been described after temporary 
ligation of the hepatic vein (Simonds and Callaway, 1932). In cats and monkeys similar lesions have been described after experimentally produced chronic venous congestion (Bolton, 1914-15). Permanent partial occlusion of the hepatic vein in dogs leads to death within $\mathbf{7 2}$ hours if the occlusion is too severe (Zimmerman and Hillsman, 1930). Two of three dogs so dying had a serosanguineous peritoneal exudate and pools of blood were present throughout the greater part of the liver lobules, but no detailed histological descriptions were given.

In rats poisoned with senecio (Davidson, 1935) the lesions are very similar to those produced by D.M.N. and there was an accompanying oedema of the parietal peritoneum. Histologically in both cases there was a sharp line of demarcation between the healthy and necrotic tissue. In senecio poisoning, however, the central veins of the liver lobules were frequently seen to have been ruptured and there was endothelial proliferation of the hepatic and pulmonary veins. Such changes were not seen in rats poisoned with D.M.N.

The cause of the haemorrhages into both the injured liver and the peritoneal cavity and lumen of the gut is not apparent. The lungs may be the seat of small haemorrhages but otherwise there seems to be no general tendency to haemorrhage outside the area draining into the portal veins.

A striking feature of the liver lesion in rats poisoned with D.M.N. is the sharp line of demarcation between the totally destroyed parenchyma and apparently uninjured liver cells. This may indicate a short-lived action of a severe, rapidly acting poison. The fact that D.M.N. is freely soluble in water means that it would probably be excreted rapidly if not quickly metabolized and broken down in the body. In the rabbit death takes place rapidly even after a dose of D.M.N. that is just lethal. In this species, few if any liver cells seem to be spared.

The way in which D.M.N. damages the liver cannot yet be surmised. If it is a rapidly acting poison it might be assumed that after oral administration the gut, portal vessels, and liver are directly damaged by the passage of D.M.N. during its absorption. The fact that similar lesions can follow the intravenous administration of D.M.N. suggests that these tissues possess some unusual susceptibility to the toxic action of D.M.N. The tendency to haemorrhage in certain species may be the result of some impairment of blood clotting-mechanisms or to action on blood vessels. If the latter is the case the peculiar distribution of the lesions might be the result of an accentuation of venous back pressure in the portal system as a sequel to the injurious action of D.M.N. on the liver. In the dog the lesions in the liver are very similar to those described in dogs killed during anaphylactic shock (Dean and Webb, 1924). On the other hand a careful examination of the intestinal mucosa in the dogs poisoned by D.M.N. failed to reveal any of the intestinal lesions said to accompany anaphylaxis in this species (Manwaring, Beattie, and McBride, 1923).

Turning to the possible chemical mechanisms whereby D.M.N. exerts its toxic action, there is again no evidence as to how this is brought about. It is conceivable that D.M.N. might be reduced, by circulating or intracellular sulphydryl groups, for example, to dimethylhydrazine. Hydrazine itself produces liver necrosis but spares other tissues (Wells, 1908).

However, preliminary observations in this laboratory by $\mathrm{W}$. N. Aldridge have shown that rabbits given dimethylhydrazine die in convulsions 24-48 hours after a dose of $100 \mathrm{mg}$. $/ \mathrm{kg}$. without histological evidence of any liver damage. Bodansky (1924) examined a number of substituted hydrazines, not however including dimethylhydrazine, and found that not all of them damaged the liver.

There remain therefore three possibilities to consider in further work on D.M.N. Dimethylnitrosamine itself may be toxic and react with some important cell constituent. It may be metabolized to produce a toxic breakdown product. Or its metabolism and breakdown may require some additional factor which, when withdrawn for this purpose, leaves the cells of the liver irreparably injured.

The experimental observations indicate that D.M.N. can produce severe liver injury in a variety of experimental animals. This makes it difficult to exclude a direct causal connexion between the handling of D.M.N. and the development of cirrhosis of the liver in two out of the three men who did so.

As a solvent D.M.N. is obviously toxic, and, from the limited experience of its use, it is clearly a dangerous one to handle despite its low volatility and consequent comparative freedom from hazards from its vapour. The absence of a strong smell or other irritant properties means that contamination of the skin and clothes may have passed unnoticed. Though it does not readily penetrate the skin of rats, it may more easily be absorbed if clothing is soaked and applied to the skin. Nevertheless there are no observations which suggest that such was the route by which the two men absorbed D.M.N. in doses sufficient to produce cirrhosis of the liver. If one assumes that man is no less sensitive than the rat, then a daily dose of $260 \mathrm{mg}$. for a man weighing $70 \mathrm{~kg}$. would be the equivalent dose to that depressing 
the growth of the rats on 50 p.p.m. in their diet. Twice such a daily dose would obviously be very dangerous. With an air intake of 5 litres per min. for seven hours a day a very dangerous level in the atmosphere would be $250 \mathrm{mg}$./cu.m. A safe atmospheric concentration would clearly have to be very much less, certainly not more than $25 \mathrm{mg}$./cu.m.

\section{Summary}

Dimethylnitrosamine (D.M.N.) is a potentially useful solvent on which little toxicity data have yet been presented.

Prompted by the occurrence of two cases of liver injury in men handling D.M.N., in the laboratory of a large firm, a study of its action on experimental animals was undertaken.

In rats, rabbits, mice, guinea-pigs, and dogs D.M.N. in doses of 20 to $40 \mathrm{mg}$. $/ \mathrm{kg}$. produces a severe liver necrosis ending fatally. Other organs are not damaged.

The lesions have some features in common with those produced by carbon tetrachloride but also some distinctive features.
In dogs, rats, and guinea-pigs a striking feature is haemorrhage into the gut and peritoneal cavity.

The features of intoxication are briefly discussed.

We wish to thank the medical officer of the firm concerned for his help and interest and for arranging for supplies of pure material. We are also very grateful to Professor G. R. Cameron, F.R.S., for his advice and help on the histological material. R. F. Legge provided valuable technical assistance.

\section{REFERENCES}

Bodansky, M. (1924). J. biol. Chem., 58, 799.

Bolton, C. (1914-15). J. Path. Bact., 19, 258.

Davidson, J. (1935). Ibid., 40, 285.

Dean, H. R., and Webb, R. A. (1924). Ibid., 27, 51.

Gomori, G. (1941). Amer. J. Path., 17, 395.

- (1950). Amer. J. clin. Path., 20, 665.

Hamilton, A., and Hardy, H. L. (1949). Industrial Toxicology, 2nd ed. Hoeber, New York.

Himsworth, H. P. (1947). Lectures on the Liver and its Diseases, p. 7. Blackwell, Oxford.

McManus, J. F. A. (1946). Nature, Lond., 158, 202.

Manwaring, W. H., Beattie, A. C., and McBride, R. W. (1923). J. Amer. med. Ass., 80, 1437.

Simonds, J. P., and Callaway, J. W. (1932). Amer. J. Path., 8, 159.

Weil, C. S. (1952). Biometrics, 8, 249.

Wells, H. G. (1908). Biometrics, 8, 249.

Zimmerman, H. M., and Hillsman, J. A. (1930). Arch. Path., Chicago, 9, 1154. 